\title{
LONG-TERM DYNAMIC MONITORING OF THE HISTORICAL MASONRY FAÇADE: THE CASE OF PALAZZO DUCALE IN VENICE, ITALY
}

\author{
J. Noh ${ }^{\text {a, }}$, S. Russo ${ }^{\text {a }}$ \\ ${ }^{a}$ University IUAV of Venice, Dept. Design and Planning in Complex Environments, via Torino, 153/A \\ 30172 Mestre (Ve), Italy - j.noh@stud.iuav.it, russo@iuav.it
}

KEY WORDS: Long-term Monitoring, Palazzo Ducale, Ambient Vibration, Dynamic Monitoring, Noise, double-leaf

\begin{abstract}
:
Long-term dynamic monitoring of the masonry façade of Palazzo Ducale known as Doge's palace in Venice, Italy was performed from September 2010 to October 2012. This article demonstrates the results of preliminary analysis on the data set of the first 12month long monitoring campaign for out-of-plumb dynamic responses of the medieval façade of the monument. The aim of the analysis of the dynamic signals is to validate the data set and investigate dynamic characteristics of the vibration signature of the historical masonry wall in the long-term. Palazzo Ducale is a heavily visited heritage due to its high cultural importance and architectural value. Nevertheless, little is known about the dynamic behaviour of the double-leaf masonry façade. In this study, the dynamic properties of the structure are presented by dynamic identification carried out with the effect of the ambient vibration measured at four different locations on the façade and portico level. The trend and intensity of the vibration at each measurement locations are identified over the year. In addition, the issue on eliminating the noise blended in the signals for reliable analysis are also discussed.
\end{abstract}

\section{INTRODUCTION}

Architectural heritage requires continual maintenance and monitoring for its safety and service to the public to share its high historical value. In particular, structural monitoring of historical constructions is of great importance in successful damage detection and timely intervention. Being acknowledged as a very effective non-destructive (ND) testing method, monitoring vibration signal of the culture heritage is widely used in conservation field since dynamic properties of the vibration are sensitive to the certain damage that often leads to change of structural integrity in the long term (De Stefano and Ceravolo, 2007; Graziera et al., 2007; Ramos et al., 2006).

This paper presents the overview of the long-term structural monitoring programme which had measured the out-of-plain motion of the historical masonry façade of Palazzo Ducale in Venice, Italy (Figure 1) and the result of the preliminary analysis of the vibration signals acquired from January to December 2011. Palazzo Ducale known as Doge's palace is one of the most recognisable architectural heritage in Venice. The icon of the lagoon city, as the political heart of The Most Serene Republic of Venice for centuries, housed the seats of the Doge, the elected leader, and the council of the Republic in the Venetian lagoon.

The monitoring campaign started in 2007 , after sudden fall of a voussior of the window arch on the east side of the balcony of the southern façade raised public awareness on the safety of the massive masonry structure. Subsequently, the city council of Venice and Venice Museum Foundation (MUVE) appointed the research unit, 'Assessment of Monumental Buildings' of University IUAV of Venice and subsequently a multidisciplinary survey programme was set up and conducted. Extensive experiments such as ND and minor-destructive (MD) geometric survey, static measurement of crack width and dynamic monitoring were conducted to investigate construction techniques, mechanical behaviour and model the out-of-plain behaviour of the historical masonry façade (Boscato et al., 2011a; Boscato et al., 2011b; Russo, 2013). In that campaign, an extensive area in the palace, mainly the walls of the Chamber of the Great Council and its adjacent chamber, has been already investigated by various test methods: geometrical survey using laser scanning over the southern and western façade, measuring the travel time of the ultrasonic wave across the several zones on the stone cladding, IR image scanning, ground-penetrating radar (GPR) survey and endoscopic survey on the interior walls.

However, very little is known about the dynamic characteristics of the ambient vibration signals for a long monitoring period. It is assumed that dynamic analysis of the motion detected from the masonry façade allows one to understand the source and trend of vibration. Furthermore, the change of the dynamic properties such as frequency, mode shape and damping can imply structural damage of the masonry. Since the damage in historical masonry is related to localised cracks and splitting of the blocks, this dynamic based non-destructive method is very attractive to capture the internal micro/macro-cracks by detecting change of global structural behaviour even at an early stage.

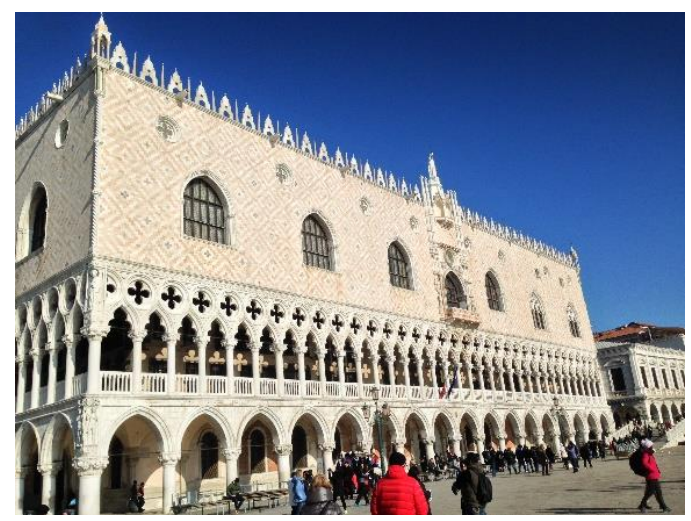

Figure 1. The southern façade of Palazzo Ducale

\footnotetext{
* Corresponding author
} 
In this article, as a preliminary damage detection of the palace, the procedure and result of the dynamic and statistical analysis of the vibration signals are represented together with the survey on construction and intervention history. The objective of this study is to validate the data set for reliable analysis and dynamic identification of the vibration signals during the given period in order to provide fundamental information for the successive potential damage detection. Signal processing techniques and statistical approach were employed to scrutinise the signals precisely.

\section{HISTORICAL SURVEY}

In this section, historical survey of Palazzo Ducale is presented focusing on the major damage, which are mostly caused by fire, and subsequent alteration to reconstruct the destroyed zones and extent its size to meet the new capacity demand as Venice prospered. Since most of the damages in heritage constructions have been passed down from the past, the knowledge of previous events and intervention history by bibliographic search is of huge importance. As a first step of damage identification of the masonry façade, the survey on the major alterations in the history of the monument proceeded the analysis of monitoring data set. The aim of the historical survey and review on the earlier research is to understand current state of the construction and find out further investigation that needs to be executed.

\subsection{History and Constructional Characteristics of Palazzo Ducale}

For almost seven hundred years, Palazzo Ducale has been subjected to several restorations. The construction of the current southern and western three-level masonry façade (Figure 1) consisting of the external stone block cladding and internal brick masonry wall were completed in 1366 and the $15^{\text {th }}$ century, respectively. After several fires that destructed partially or extensively the palace and alteration due to end of dogeship in Venice, a notable restoration of the southern and western façade was conducted by Annibale Forcellini between 1875 and 1890 . The intervention included replacing the old original columns and capitals in the portico and loggia level, introducing new steel ties in the loggia and fixing the earlier restored areas. His report presents detail of the restoration work and a great deal of drawings of the elements. The previously removed balconies in both façades were reconstructed between 1852 and 1854. After annexation of Venice to the Kingdom of Italy in the 20th century, the palace underwent substantial renovation to eliminate the public offices used by the foreign powers.

Palazzo Ducale consists of three main wings in west, south and east and northern side attached to the adjacent St. Mark's Basilica encompassing the large courtyard as shown in Figure 2.

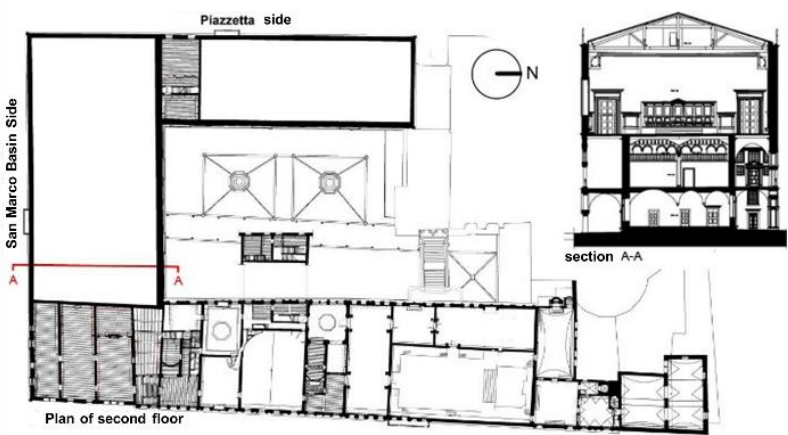

Figure 2. Plan view of the ground level and section view of southern façade of Palazzo Ducale
The southern and western façades are comprised of four levels: ground level surrounded by arcades (portico), second level with loggia, third level with stone cladding and roof level with the cornice. The third level of each medieval façade is $11.16 \mathrm{~m}$ high and the double-leaf masonry is composed of $0.9 \mathrm{~m}$ thick internal clay brick masonry and external polychrome stone cladding of various thickness stone blocks. The square and rectangular blocks have same height, but different width and depth and form the periodic lozenge patterns all over the façade. The colour of the blocks differs for the type of the stone: Istrian stone, red Veronese marble and ancient marble. It is noted that the Istrian blocks have larger thickness up to $25 \mathrm{~cm}$ than others and it is believed that those deeper blocks play a role as a key which transfers the weight of the external cladding to the internal loadbearing masonry wall. This double-leaf façade is very common construction technique in Venice to protect the porous clay brick masonry exposed to the saline environment in the lagoon. The feature of the key and the interface of the two-leaf masonry wall shall be noted since the structural behaviour of the two layers may be different from each other. Subsequently, the different structural behaviour of each leaf may relate to the damage in the masonry such as crack propagation and block splitting.

\subsection{Previous Structural Surveys}

According to the Malvezzi's report in 1874, he investigated the stability of the façades and found no specific cracks and settlement of the walls. His finding was most likely due to that sound state of the foundation that is capable of adopting widespread settlement by its plastic behaviour. His survey also identified the uniform thickness of the internal load bearing wall $(90 \mathrm{~cm})$ and the masonry walls are slightly inward-inclined as a passive safety method that is widely used in Venetian constructions. This inclination is related to the eccentricity found between the base of the wall and the centre of the columns in the loggia level. Thus, it can be inferred that the masonry wall level set back a bit with respect to the lower levels. The dimension of the unit in the interior brick wall was measured $(70 \times 135$ $150 \times 280-300 \mathrm{~mm}^{3}$ ) and this peculiar size can be found in many load bearing wall of Venetian Gothic architecture.

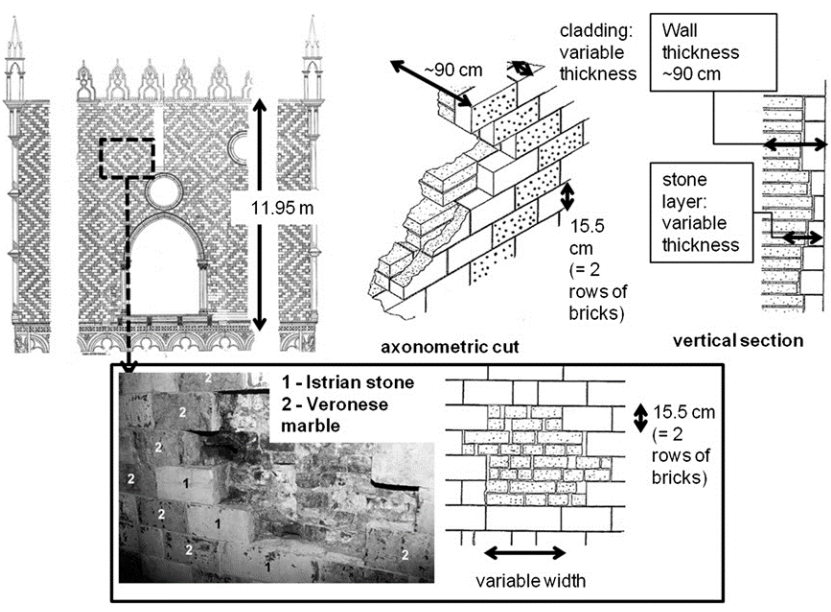

Figure 3. Details of the façade (Russo, 2013)

Between 1997 and 2003, another extensive restoration took place. Schuller conducted visual inspection of the façades and, based on his finding, he claimed that the external stone cladding would have been constructed after the internal brick masonry is complete. On the contrary, Romanelli et al. deduced that the internal and external walls were constructed at the same time due to the fact that the height of two courses of brick masonry 
coincides with the height of one external stone block as shown in Figure 3. However, no regular brick patterns were identified in the investigated load-bearing walls.

\section{DYNAMIC MONITORING}

\subsection{Measurement Setup}

The data set, which is composed of the in-plane and out-of-plane motions of the masonry wall and the capital of the column in portico level, had been recorded at four different locations on the southern façade of the palace for 16 months from September 2010 to October 2012. The single data file contains the acceleration signals from six channels corresponding to three piezoelectric uniaxial accelerometers and one piezoelectric triaxial accelerometer and those data were stored on a daily basis. The accelerometers have nominative sensitivity equal to $1000 \mathrm{mV} / \mathrm{g}$ with frequency range $( \pm 5 \%)$ from $0.0025 \mathrm{~Hz}$ to 800 $\mathrm{Hz}$ for uniaxial sensor and from $0.5 \mathrm{~Hz}$ to $3000 \mathrm{~Hz}$ for triaxial one. The location of the sensors and axes convention for the motion are illustrated in Figure 4. Three uniaxial accelerometers attached to the surface of the southern façade are referred to as AM1, AM2, AM3 from top to bottom together with one triaxial accelerometer as AT1. Aligned vertically, the sensors were placed next to the window whose one of the voussior has fallen in 2007. The elevation of AM1 and AM3 corresponds to the almost upper end of the façade and the floor level of the interior chamber, respectively, and the AM2 installed in the middle because it was assumed that those locations are sensitive to the out-of-plain motion.

The real-time measurement produces basically out-put-only data which is triggered by the ambient vibration whose amplitude exceeds the pre-defined thresholds which are equal to $0.001 \mathrm{~g}$ for AM1, AM2 and AM3, 0.005g for AT-X and AT-Y and 0.05g for AT-Z. Practically the relationship between the physical quantities of vibration such as acceleration and velocity and the onset of cracks or splitting of the historical masonry constructions has not been clearly accounted for. As per ISO code (ISO 4866, 1990), the typical range of the accelerations induced by traffic is $20-1000 \mathrm{~mm} / \mathrm{sec}^{2}(0.002-0.1 \mathrm{~g})$. The thresholds above are of similar value to the lower bound of the traffic band. Recording durations ranges from 20 to 60 seconds once measurement is triggered. Those short measurement duration is too short to analyse steady-state vibration and perform system identification of the structure.

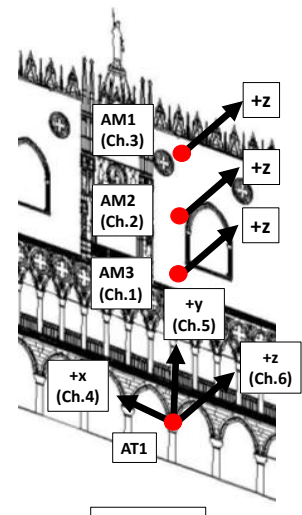

Initial setup

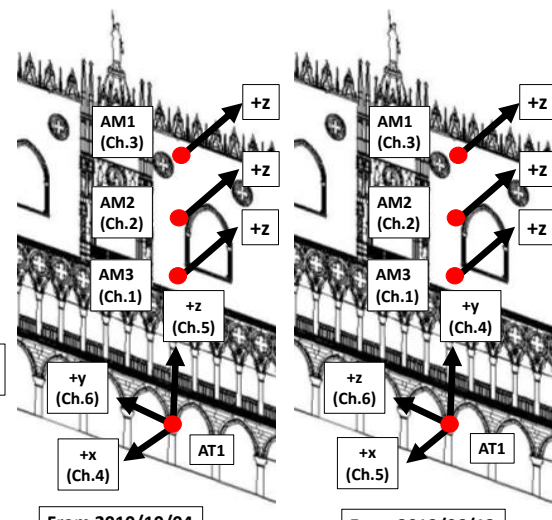

From 2012/06/12
Figure 4. Setup of the accelerometers on Southern façade

\subsection{Data Validity Check}

\subsubsection{Overview of the raw signals}

Before processing whole data set, it is necessary to check the validity and accuracy of the data in order to rule out abnormal signals such as electrical noise and disturbance that are not related to the responses of the structure. In the long-term structural monitoring of historical buildings, reliability of the data is of huge importance since the behaviour of the masonry is often nonlinear and irrelevant electrical signals can be included in the data set due to instrumental malfunction. Thus, maintenance of the data acquisition system and its stable operation with minimum non-structural responses shall be assured for successful monitoring.

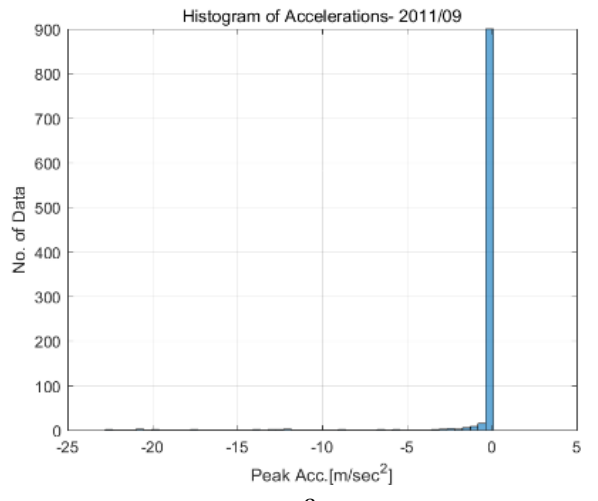

a

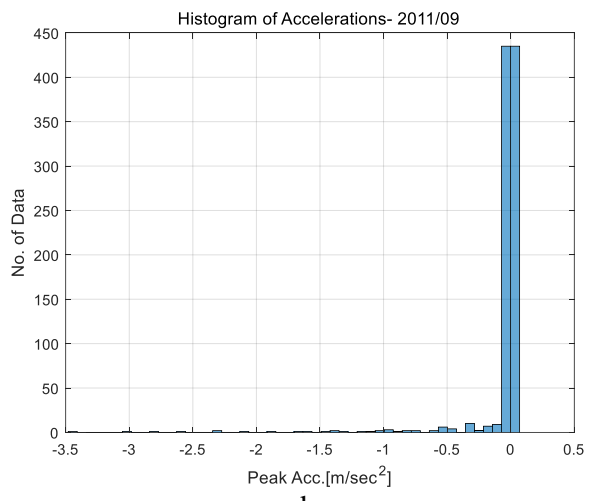

Figure 5. Histogram of peak accelerations (September 2011): a. raw signals and b. signals within $95 \%$ confidence interval

To facilitate the data validation, the huge data set of the long-term measurement is divided into the groups of one month. The signals in each monthly group is scrutinised to understand if the data is clean enough to provide reliable results with only respect to structural behaviour. For example, the distribution of the peak accelerations of the raw signals in September 2011 are presented in Figure 5a. This diagram is known as histogram and illustrates the frequency density corresponding to the variable which is the peak acceleration of each signal. The horizontal axis represents the peak acceleration values in 50 equal ranges as referred to as 'bin' proportional to the number of the cases (frequency or population) in the vertical axis. As seen, most signals in October lie within the range between -1 and $0.01 \mathrm{~m} / \mathrm{sec}^{2}$ (the tallest bar) while a few data exhibit much higher peak accelerations up to approximately $-23 \mathrm{~m} / \mathrm{sec}^{2}$ that is unrealistic in case of buildings. It is obvious that the extraordinary values be found at certain time period in September 2011 as shown in Figure 6. The maximum peak acceleration, for instance, took place at $16: 37: 33$ in $19^{\text {th }}$ September 2011 at AM3 and AM1. Considering the unrealistic 
amplitude and the waveform in time series shown in Figure 7, those abnormal signals are most likely to be measurement failure so that they shall be removed in further processing.

In similar fashion, all signals stored in 2011 were processed. The signals of 2011 are presented in Table 1 and Figure 8. $\boldsymbol{N}_{\text {raw }}, \boldsymbol{a}_{\text {raw }}$, $\mu$ and $\sigma$ in the table present the number of the raw signals measured each month, monthly raw mean peak acceleration, mean value and standard deviation, respectively. It is noted that $\boldsymbol{N}_{\text {raw }}$ and $\boldsymbol{a}_{\text {raw }}$ of each month vary significantly. Moreover, most monthly peak accelerations are so large that it cannot be considered as actual structural responses, but measurement failure. As a first step of the signal processing, the samples containing unacceptable accelerations shall be eliminated for reliability. However, it is almost impossible to distinguish abnormalities from whole data set by checking each waveform of more than 60,000 data files. Using MATLAB ${ }^{\circledR}$ programming, thus, automatic cancelling of the data file containing such measurement failure was employed.

\subsubsection{Removal of false signals}

The quick overview on the yearly data set clearly indicates that there exist a great deal of signals which contain statistically insignificant samples and, subsequently, shall be removed. One of possible criteria to get rid of the abnormal signals from the copious samples is the amplitude of the peak acceleration. At this point, the range of the real structural response of the masonry façade is still so uncertain that distinguishing 'clean' signals from the contaminated data set is difficult. Another secure way is, as mentioned before, viewing the waveform of each signal. Due to the huge number of samples, therefore, a statistical approach is used to cancel the undesired data before analysing the data set.

According to probability theory (Feller, 2008), it is assumed that all random variables follow the normal distribution if the number of the variables is sufficiently large and can be expressed in probability density function (PDF). Many classical statistical tests are based on this assumption and the normal distribution is used to find significance levels in many hypothesis tests and confidence intervals. The probability density function of the normal distribution is:

$$
P(x)=\frac{1}{\sigma \sqrt{2 \pi}} e^{-(x-\mu)^{2} /\left(2 \sigma^{2}\right)}
$$

where, $x$ is random variable, $\sigma$ is standard variation and $\mu$ is mean. The PDFs of all peak accelerations of AM1, AM2 and AM3 in 2011 are illustrated in Figure 9. For comparison, the variables in the horizontal axis are normalised by the maximum value of each sensor. The normalised mean $\mu_{N}$ is presented in the dotted red lines and the lower and upper bounds of $95 \%$ confidence interval are presented in black solid lines. Although the distributions are biased to the negative side, the reasonable PDFs are obtained and the statistically significant peak accelerations within $95 \%$ confidence interval can be selected. The background theory and calculation of the confidence interval is also presented in (Feller, 2008). As presented in Table 1, the number of the signals $\left(\mathrm{N}_{95}\right)$, mean peak acceleration $\left(\boldsymbol{a}_{95}\right)$ and standard deviation $(\sigma)$ are significantly reduced after trimming the samples whose peak values lying outside the $95 \%$ confidential interval. In Figure $5 b$, the histogram of the data set of September 2011 are presented lies within a much smaller range of acceleration (horizontal axis) than the raw data set. Thus, the trimmed data set can be deemed a lot more reliable. For instance, Figure 10 exhibits the comparisons of the PDFs of the raw data set and those of the signals within $95 \%$ confidential interval. The number of abnormal amplitude of peak accelerations are drastically reduced in AM3 (Figure10 a) while there still exist a lot of abnormal peak values of Ch.5 despite reducing the data set in a same way. Thus, the signals of Ch.4 and Ch.5 are excluded in this analysis for more reliable overall outcomes.

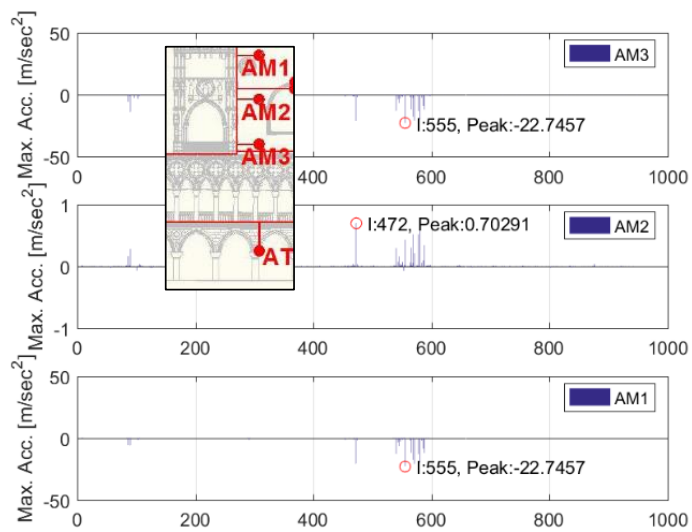

Figure 6. Maximum peak accelerations during one month: September 2011
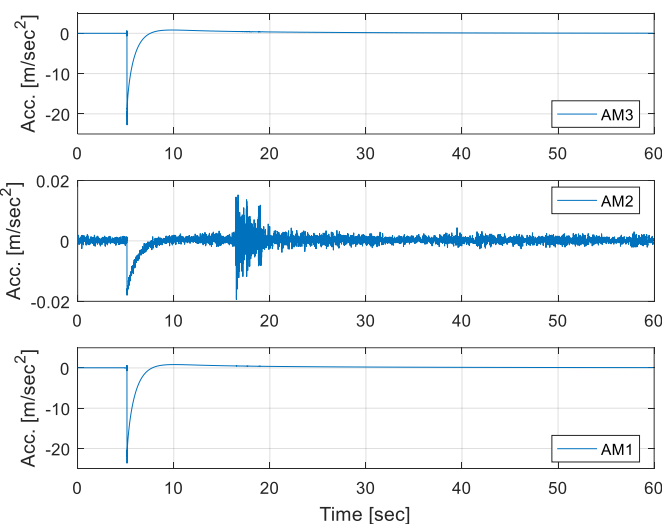

Figure 7. Accelerogram of the signals at 16:37:33 on 19th September 2011

Table 1 Monthly maximum acceleration: 2011

\begin{tabular}{crrrrrr}
\hline & $N_{\text {raw }}$ & \multicolumn{1}{c}{$\boldsymbol{N}_{95}$} & $\begin{array}{c}\text { Red- } \\
\text { uction } \\
{[\%]}\end{array}$ & $\begin{array}{c}\boldsymbol{a}_{\text {raw }} \\
{\left[\mathbf{m} / \mathbf{s e c}^{2}\right]}\end{array}$ & $\begin{array}{c}\boldsymbol{a}_{95} \\
{\left[\mathbf{m} / \mathbf{s e c}^{2}\right]}\end{array}$ & $\begin{array}{c}\text { Red- } \\
\text { uction } \\
{[\%]}\end{array}$ \\
\hline Jan & 194 & 194 & 0 & -0.05 & -0.06 & 0 \\
\hline Feb & 389 & 385 & 1.0 & 0.05 & 0.68 & 0 \\
\hline Mar & 973 & 813 & 16.4 & -12.84 & -0.45 & 96.46 \\
\hline Apr & 1,063 & 903 & 15.1 & -19.01 & -1.34 & 92.96 \\
\hline May & 1,275 & 1,011 & 20.7 & -25.19 & 0.58 & 97.69 \\
\hline Jun & 1,750 & 979 & 44.1 & -25.75 & 0.67 & 97.39 \\
\hline Jul & 2,266 & 1,896 & 16.3 & -22.44 & -3.26 & 85.49 \\
\hline Aug & 761 & 759 & 0.26 & -7.55 & -1.73 & 77.11 \\
\hline Sep & 949 & 936 & 1.37 & -22.75 & -3.43 & 84.91 \\
\hline Oct & 1,257 & 1,246 & 0.88 & -24.57 & -2.66 & 89.18 \\
\hline Nov & 318 & 308 & 3.14 & -0.91 & -0.91 & 0.00 \\
\hline Dec & 319 & 310 & 2.82 & -4.21 & -3.33 & 21.07 \\
\hline Sum & 11,514 & 9,740 & 15.4 & & & 90.78 \\
\hline$\mu$ & & & & -13.77 & -1.27 & \\
\hline$\sigma$ & & & & 10.20 & 1.60 & \\
\hline
\end{tabular}




\subsection{Analysis of Dynamic Signatures}

Subsequently, the analysis of the processed data set of 2011 is discussed. Figure 11 presents the number of hourly collected signals for a day. There is no big difference in distribution between the raw and processed data set. The vibrations that surpassed the threshold took place mostly during the opening hours of the museum from 08:30 to 17:30 in winter and to 19:00 in summer so the diagram indicates that the visitors traffic is the main source of the vibration on the masonry façade of interest. For the raw data set, however, the intensity of the vibration during the office hours is very much lower than outside of office hours as shown in Figure 12 while the signals of 95\% confidence level do not show significant fluctuation across the measurement time. This discrepancy demonstrates the fact that the abnormal signals take place mostly during outside of the office hour despite very small population of the samples. In addition, it can be inferred that the noise is not usually triggered by heavy traffic, but other sources that frequently occurred particularly from 18:00 to 03:00 in the following days. The properties and causes of latenight abnormalities are not clear.

Meanwhile, Figure 13 provides useful information that may indicate more sensitive part of the masonry façade to the dynamic load. For the data set of 95\% confidence level (filled black bars), the mean peak value of the out-of-plain acceleration of the stone cladding measured at AM1 and AM3 are 3.17 times and 1.5 times that of AM2. The possible reason for the higher vibration level at AM1 and AM3 than AM2 is that the timber beams of the floor in the Chamber of the Great Council which is the most spacious in the palace are embedded in the internal masonry at the level of AM3 so the vibrations due to the heavy traffic of the visitors can be transmitted to the nearby sensor (AM3). However, the link between the higher response amplitude observed at AM1 level and its location is not certain. Comparison between the mean peak accelerations of the raw data set and the signals within $95 \%$ confidential interval shows that the abnormal signals were successfully reduced and the reliability of the results is improved considerably.

Finally, the frequency components of the all signals are calculated using Fast Fourier Transformation. In order to make the main frequency components remarkable, a series of preprocess were carried out as follows: 1) removing the linear trend (mean value), 2) filtering, 3) choosing only post-peak vibration 4) application of Hanning window and 5) Fast Fourier Transformation. Having performed FFT with the raw data, a prevailing frequency component was observed near $50 \mathrm{~Hz}$ which is a typical noise featured by electric hum as known as mains hum (Figure $14 \mathrm{a}$ ). This noise is associated with alternating current at the frequency of the mains electricity which is $50 \mathrm{~Hz}$ in Europe. If the circuit ground is not properly connected with the earth, the frequency of the current is blended in the measurement. This mains-hum-affected range of frequencies between 47 and $51 \mathrm{~Hz}$ can be easily eliminated by employing Butterworth notch filter (Figure 14 b).

Figure 15 presents the filtered accelerogram and spectrum of a typical signal measured at sensor AM2 at 10:06:10 on $25 / 06 / 2011$. The peak acceleration is highlighted in the red circle in Figure 15a and first 30 high frequencies in frequency domain are also indicated in the red circles in Figure $15 \mathrm{~b}$. The corresponding first 10 frequencies are 7.83, 7.01, 7.21, 3.39, $7.47,6.60,8.39,6.72,3.55$ and $5.86 \mathrm{~Hz}$. In most cases of the spectral analysis, the peaks of the spectra are very close to each other so determining peaks (modes) is difficult. The distribution of the first 30 high frequencies of all signals of the sensor AM1,
AM2, AM3 and Ch.6 in 2011 are illustrated in Figure 16. As for the uniaxial accelerometers (AM1, AM2 and AM3), most frequencies are found in the range between 0 to $21 \mathrm{~Hz}$ while most frequencies of the Ch. 6 lie in the vicinity of $0 \mathrm{~Hz}$ and the population of frequency components decreases exponentially toward higher frequencies.

Apart from the identified vibration sources, the link between the dynamic response and other vibration sources such as fireworks, earthquakes, bell tolling from the belfry near the palace, etc. needs to be further investigated to ascertain their effect on the historical masonry wall. In addition, evaluation on the equivalent velocity and displacement calculated from the measured acceleration is required to check if those responses meet the safety and serviceability criteria in the norms available. Although the amplitudes of the most ambient vibration in the data set are very small and the measuring duration of the accelerogram is not long enough, damping can be also assessed.

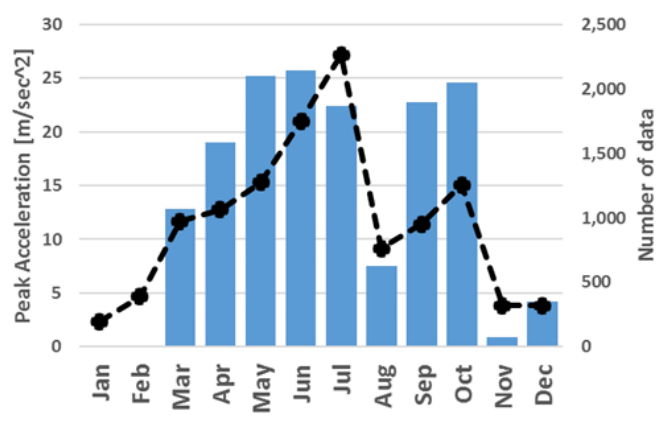

Figure 8 . The monthly peak accelerations (bar) and the number of the raw signals collected in 2011 (dashed line)
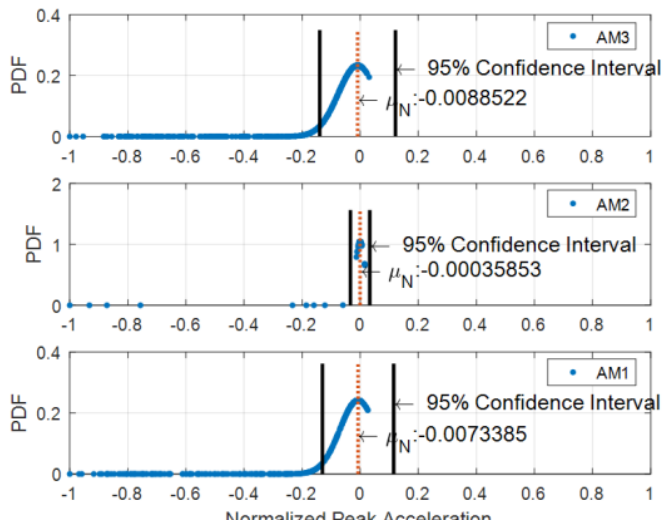

Figure 9 Probability density curves of the raw signals

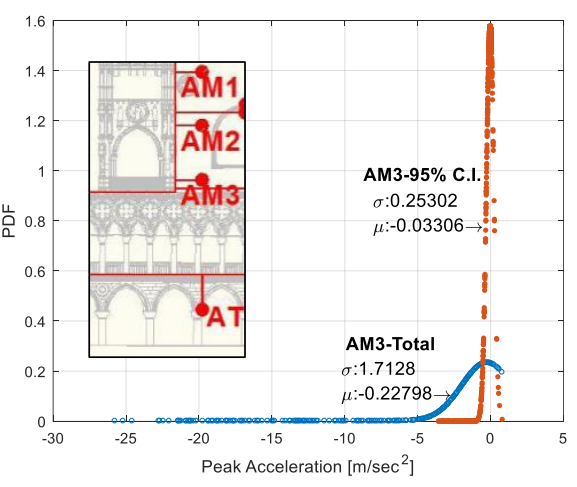




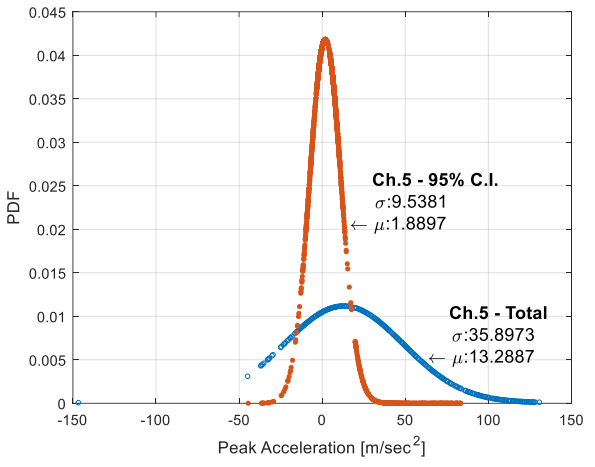

$\mathrm{b}$

Figure 10 Comparison of the PDFs by the raw data set with the signals within 95\% confidence interval: a. AM3 and b. Ch.5 (AT)

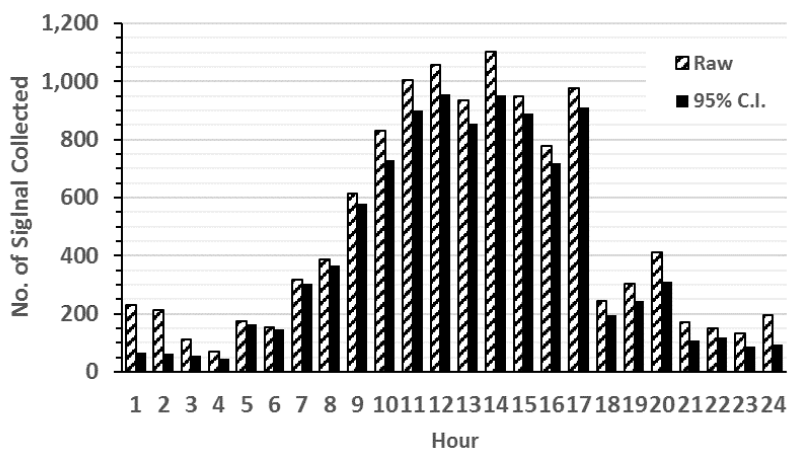

Figure 11 Hourly number of signals collected in 2011

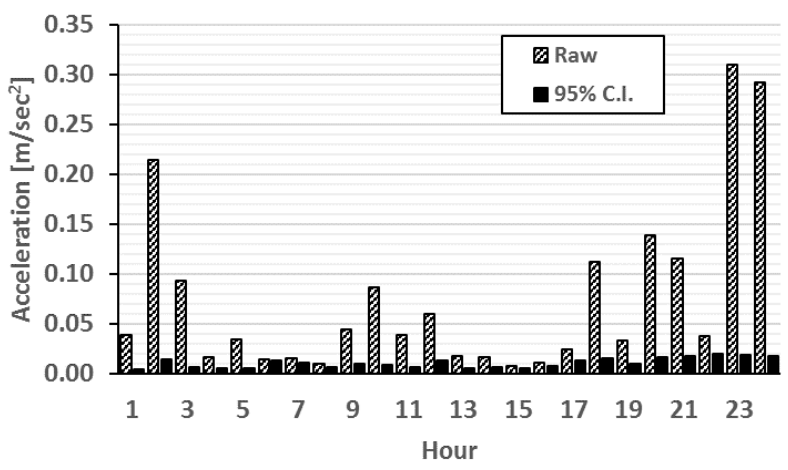

Figure 12 Hourly mean peak acceleration in 2011

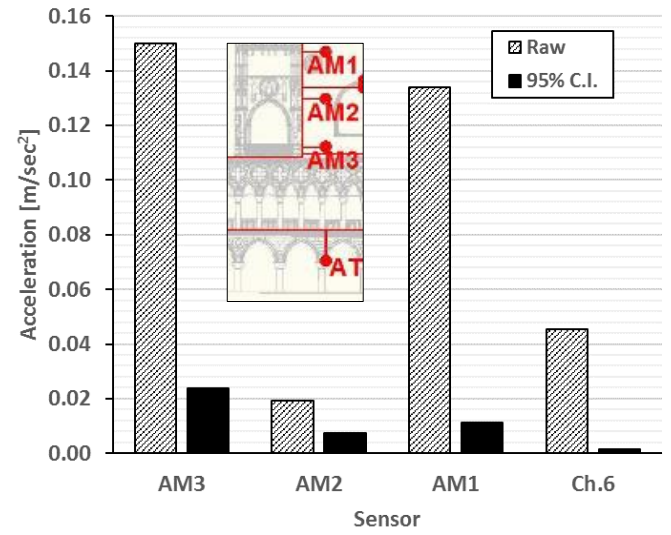

Figure 13. Annual mean peak acceleration at each channel in 2011
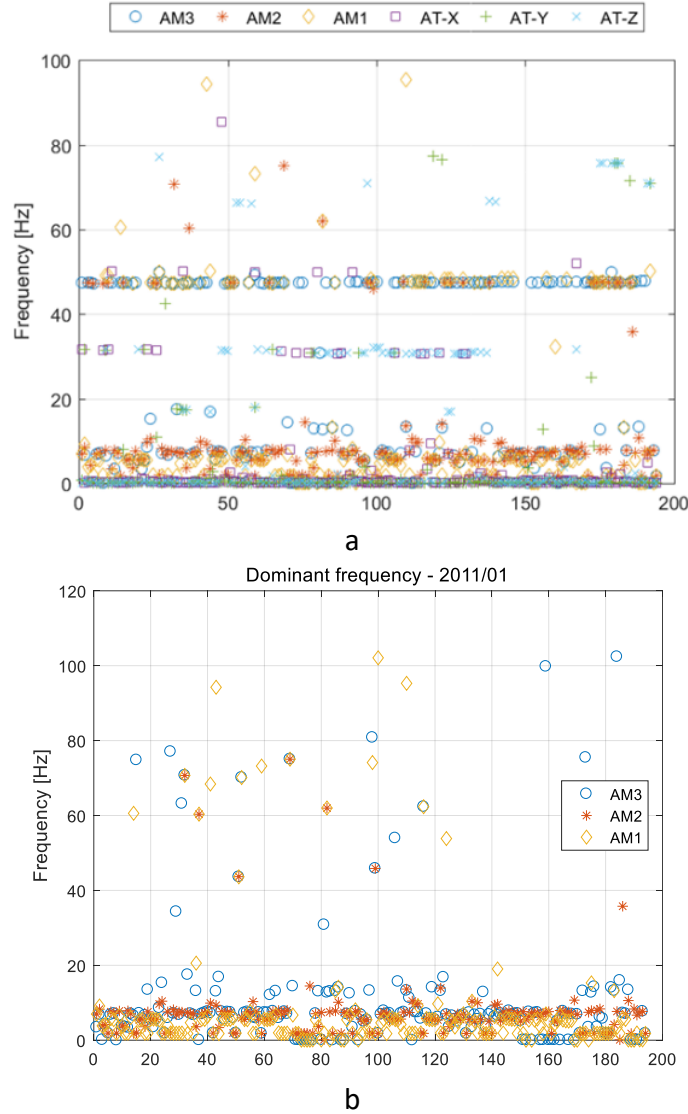

Figure 14 Dominant frequencies of all sensors for a month (Jan. 2011): a. raw data set and b. filtered signals

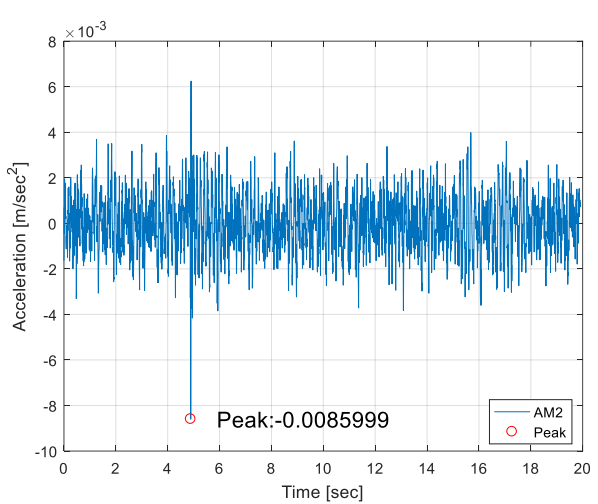

a

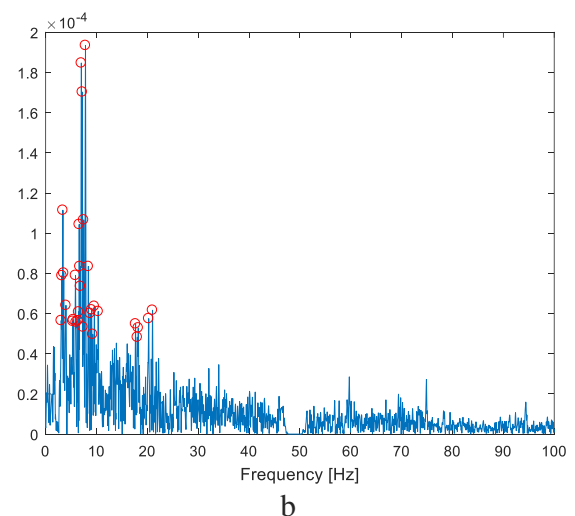

$\mathrm{b}$

Figure 15. Accelerogram and spectrum by FFT of the signal at 10:06:10 in $25^{\text {th }}$ June 2011 

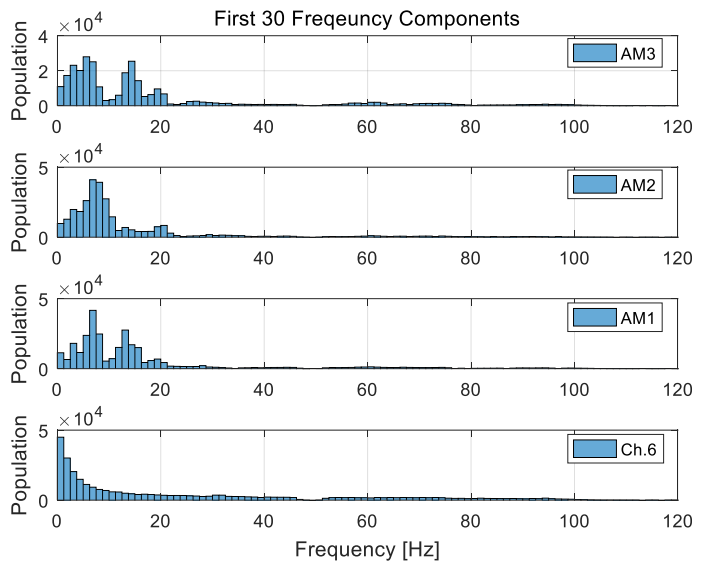

Figure 16. Histogram of first 30 frequencies: 2011

\section{CONCLUSION}

The preliminary dynamic analysis of the long-term signals provided basic and essential knowledge for the ultimate purpose of the structural monitoring of the masonry façades of Palazzo Ducale: assessing the structural safety and detecting local damage. The key findings of this study are as follows:

I. The raw data set contains a significant number of abnormal signals that mislead and mask the real structural behaviour;

II. The statistical noise cancellation can reduce dramatically the number of contaminated signals and the overall mean peak acceleration;

III. Not only the abnormal amplitude of the signals, but also other noises such as mains-hum in frequency domain are blended in the data set and those are successfully eliminated;

IV. The number and amplitude of signals increases as the traffic increases during the warmer seasons and office hours of the museum, but the abnormal signals occur mainly between 18:00 and 03:00 in the following days;

V. Sensitive locations showing the larger dynamic responses are the floor level of the Chamber of the Great Council (AM3);

VI. Most frequency components of all signals are observed between 0 and $20 \mathrm{~Hz}$.

Those findings can be developed to propose a solution for general problems in monitoring historical buildings such as noises and nonlinear dynamic behaviour of the massive double-leaf masonry wall in the future work.

The limitation of previous monitoring programme is that the setup to record the dynamic response cannot provide sufficient information for system identification. For operational modal analysis, measuring duration of ambient vibration shall be extended. Furthermore, additional sensors along the horizontal direction are beneficial to understand more accurate out-of-plain behaviour of the historic masonry façade and 2-dimensional FE modelling of the historical façade.

\section{ACKNOWLEDGEMENT}

The authors warmly thank Dr. Giosuè Boscato and Dr. Francesca Sciaretta for their help and support. This research have used the scientific equipment acquired by the IUAV laboratories (LabSco) of innovation for architecture of the University IUAV of Venice.

\section{REFERENCES}

Boscato, G., Riva, G., Russo, S. et al., 2011a. ND tests for a first assessment of mechanical behaviour of the stone-covered façades of Palazzo Ducale in Venice. In Proceedings of Structural Repairs and Maintenance of Heritage Architecture XII, pp. 615625.

Boscato, G., Russo, S., Sciarretta, F., 2011b. Structural Monitoring of the Slender Double-Layered façade of Palazzo Ducale in Venice - Preliminary Analysis of Measurements. Journal of the International Masonry Society, Vol 24, No. 3, pp. $57-72$.

De Stefano, A. and Ceravolo, R., 2007. Assessing the Health State of Ancient Structures: The Role of Vibrational Tests. Journal of Intelligent Material Systems and Structures, Vol. 18, pp. 793-807.

Feller, W., 2008. An Introduction to Probability: Theory and its Applications, $3^{\text {rd }}$ Edition, Wiely.

Forcellini, A., 1887. Relazione consustative dei lavori svolti, Conv. Ingegneri veneziani, Italy.

Graziera, R., Amabili, M. and Collini, L., 2007. Structural health monitoring techniques for historical buildings. IV Conferencia Panamericana de END, Buenos Aires, Argentina.

ISO 4866, Mechanical vibration and shock vibration of buildings, Guidelines for the measurement of vibrations and evaluation of their effects on buildings, 1990.

Malvezzi, G., 1884, Delle assicurazioni provvisorie per restauro generale delle due principali facciate del Palazzo Ducale di Venezia, Giornale del Genio Civile n. 24, pg. 124-136., Italy

Ramos, L., De Roeck, G., Lourenço, P. and Campos-Costa, A., 2006. Vibration Based Damage Identification of Masonry Structures. International Conference on Structural Analysis of Historical Constructions, New Delhi, India.

Romanelli, G., Andreozzi, D., Smith, M. et al., 2004. Palazzo Ducale: storia e restauri, Verona: Banco Popolare di Verona e Novara, Italy.

Russo, S., 2013. Testing and modelling of dynamic out-of-plane behaviour of the historic masonry façade of Palazzo Ducale in Venice, Italy. Engineering Structures 46 (2013), pp. 130-139.

Schuller, M., 2000. Il Palazzo Ducale di Venezia. Le facciate medioevali, Atti del Convegno sul Gotico veneziano, Istituto Veneto di Scienze Lettere ed Arti, Venezia, Italy. 